\title{
Recovering vanadium during the production of steel from iron sand
}

\author{
Winston L. Sweatman ${ }^{1} \quad$ Graeme C. Wake ${ }^{2}$ \\ Luke Fullard ${ }^{3} \quad$ Maria Bruna ${ }^{4}$
}

(Received 14 September 2011; revised 5 April 2012)

\begin{abstract}
This project considers the retrieval of vanadium and similar valuable by-products when producing steel from iron sands. This recovery should be optimised without compromising steel production. The process is modelled with a system of differential equations. A method is outlined that optimises vanadium recovery once parameters have been identified experimentally.
\end{abstract}

\section{Contents}

http://journal. austms.org.au/ojs/index.php/ANZIAMJ/article/view/4674 gives this article, (c) Austral. Mathematical Soc. 2012. Published May 26, 2012. ISSN 1446-8735. (Print two pages per sheet of paper.) Copies of this article must not be made otherwise available on the internet; instead link directly to this URL for this article. 
2 The operation of the vanadium recovery unit during steel production

M3

3 Model for the main oxidation process in the VRU

M6

4 Model parameters

M10

4.1 Chemical variables $[\mathrm{P}] \ldots \ldots \ldots \ldots$

4.2 Rate constants . . . . . . . . . . . . . M11

4.3 Mass flow rates . . . . . . . . . . . . . . . . . . M12

4.4 Heat transfer and generation . . . . . . . . . . . M13

4.5 Initial conditions . . . . . . . . . . . . . . M16

5 Numerical experiment

M16

6 Discussion

M17

7 Conclusions

M20

References

M21

\section{Introduction}

Early in steel production from iron sands it is necessary to remove vanadium and other metalloids. These are also a valuable by-product. The goal of the New Zealand Steel problem at the 2011 Mathematics-and-Statisticsin-Industry Study Group (MISG) was to progress towards modelling and optimising this extraction.

Section 2 describes the relevant processes at the steel mill, and in particular the operation of the vanadium recovery unit (VRU). Section 3 characterises the processes in the VRU by chemical reactions, and the progression of these are modelled by a system of differential equations. 
The differential equations involve many parameters. Unfortunately, in many cases, these proved unavailable. However, Section 4 attempts to identify some plausible model values. Section 5 describes a simple numerical realisation of the model with illustrative results. Strategies to improve the model and possible future directions are discussed in Section 6 before the report is concluded in Section 7.

\section{The operation of the vanadium recovery unit during steel production}

New Zealand Steel produces iron and steel from iron sand (titanomagnetite). The iron sand is formed through the breakdown of rocks originating from volcanic activity in Taranaki 2.5 million years ago. Over time, the heavy, dark sands are transported by ocean currents and deposited on beaches. New Zealand Steel collects iron sand from the mine site at the north head of the Waikato river and transports it $18 \mathrm{~km}$ to the Glenbrook mill, near Auckland, for processing. The iron sand is reduced by mixing it with coal and heating it (as a solid) in rotary kilns. The raw iron produced is then melted and tapped into ladles (tall metal containers). The ladles are used to transport the raw iron around the mill as well as through the next stage in the metal processing. The raw iron in the ladle averages 71 tonnes. Its chemical composition is variable and is sampled at this point. The molten metal contains residual carbon from the coal. This carbon is required later in the steel-making process. There are also a number of metalloids present including vanadium, manganese, silicon and titanium. The metalloids are removed, as far as it is possible, when the ladle passes through the VRU. The processes occurring in the VRU were the focus of the study group, they are illustrated in Figure 1.

It is desirable to oxidise and remove the metalloids at the VRU as their presence makes the later steel-making process more expensive (requiring more lime $\mathrm{CaO}$ and magnesium oxide $\mathrm{MgO}$ ). Further, the metalloids are valuable 


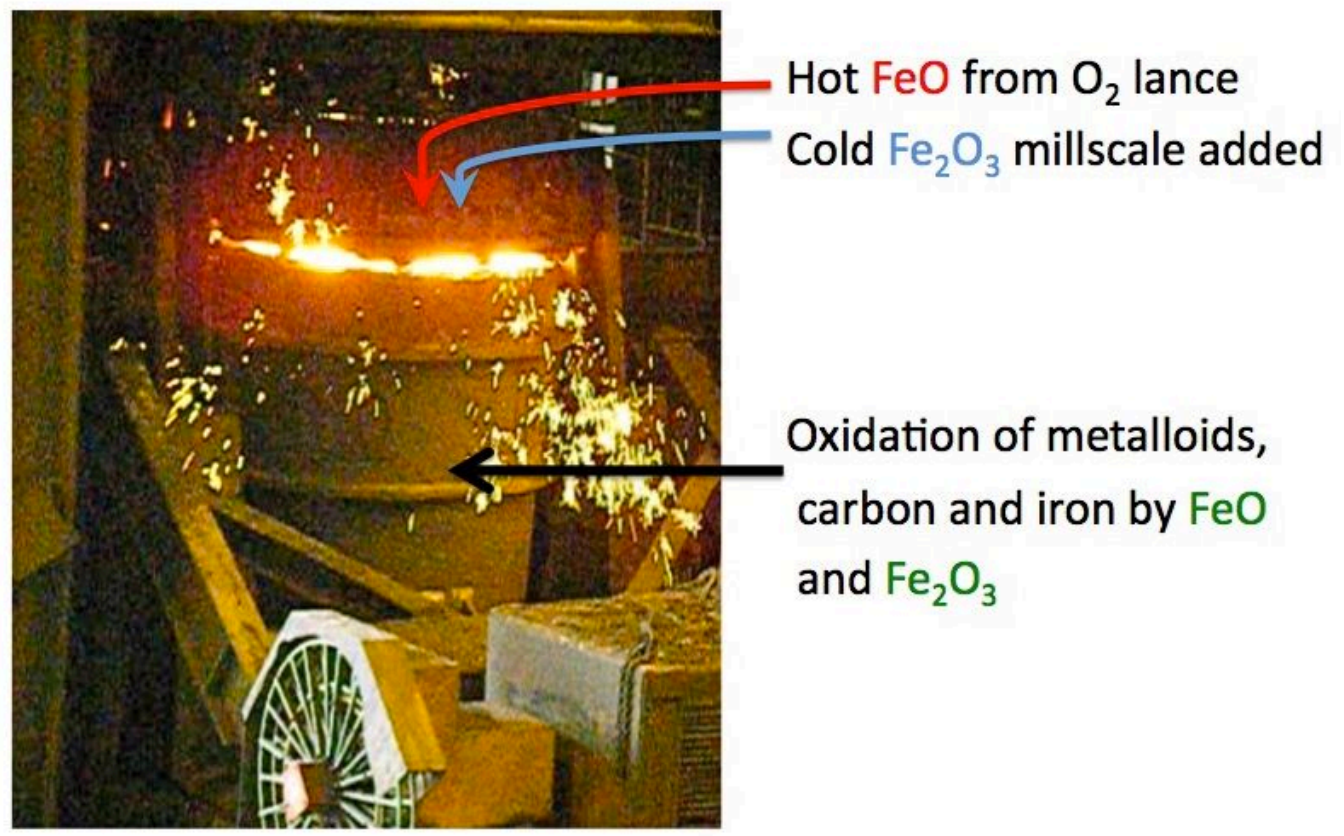

Figure 1: Processes occurring in the ladle at the vRU (photograph courtesy of New Zealand Steel).

as a by-product: vanadium is a precious metal which, among other things, has been used to make high energy density lithium ion batteries and a specific type of superconducting magnet. Apart from its operation to oxidise and remove metalloids the VRU is also used to maintain the ladles. Sometimes molten iron solidifies to form what is called a skull on the walls of a ladle. This is undesirable, and operators use the VRU to melt off skulls. To do this they may use two or three VRU processings to melt off a three tonne skull. During this time this process is prioritised over vanadium recovery.

In the VRU, vanadium and the other metalloids are extracted through oxidation. This produces a lower density slag which operators mechanically scrape off the surface of the ladle. Oxygen is provided by one of two mechanisms: 
gaseous oxygen may be blown directly onto the liquid iron surface using an oxygen lance; or a solid millscale powder of iron oxides may be added to the ladle and the reduction of this indirectly provides oxygen. The contents of the ladle are well-mixed due to the action of a nitrogen lance blowing $\mathrm{N}_{2}$ gas at $35 \mathrm{~m}^{3} / \mathrm{h}$ into the liquid metal.

The oxygen lance blows $\mathrm{O}_{2}$ at a rate of $1200 \mathrm{~m}^{3} / \mathrm{h}$. This operates continuously throughout most of the action of the VRU, on average supplying $270 \mathrm{~m}^{3}$ of oxygen. The exact positioning of the lance is adjusted manually. The oxygen rapidly reacts at the surface of the metal liquid where the flame temperatures reach above $2000^{\circ} \mathrm{C}$. The action of the oxygen and nitrogen lances quickly mixes the products (expected to be mainly iron oxide $\mathrm{FeO}$ ) throughout the ladle where the oxidation process takes place. Addition of oxygen through the oxygen lance has the effect of increasing the ladle contents' temperature.

Millscale is a solid powder composed mainly of iron oxides, primarily $\mathrm{Fe}_{2} \mathrm{O}_{3}$. The millscale is added in up to three discrete batches each of $1000-1500 \mathrm{~kg}$ at room temperature. The millscale heats to the temperature of the ladle contents, melting in the process so that it can react with other species. It appears to take about five minutes for this entrainment. Typically $1100 \mathrm{~kg}$ of millscale is added at the start of the process. Overall, the effect of millscale addition appears roughly temperature neutral.

The oxidation and recovery process is constrained by the need to avoid carbon oxidation. As well as being required for the later processing to create steel, carbon oxidation may result in 'carbon boil'. This is an instability of the system where there is a runaway production of carbon monoxide CO and heat, causing the iron to erupt, overflow the ladle, and damage plant equipment. Carbon monoxide bubbles do not readily form in liquid iron and this may cause oxygen to supersaturate. However, rough surfaces of undissolved millscale or metal skulls can encourage bubble nucleation. The relative rate of metalloid oxidation decreases with increasing temperature, while the carbon reaction rate increases for higher temperatures. Carbon oxidation is also more likely to occur late in the recovery process when the 
metalloids have been largely oxidised and their concentration in the molten iron is relatively low. Carbon boil can be prevented by keeping oxygen concentrations sufficiently low through maintaining silicon concentration at a sufficiently high level, adding iron silicon alloy FeSi if necessary. Routinely about $105 \mathrm{~kg}$ FeSi is added 1-2 minutes before the end of the oxygen lance blow. Some acidic oxides are required later in the steel processing and the iron silicon alloy FeSi addition also contributes to this forming $\mathrm{SiO}_{2}$.

The temperature range of the ladle has to be kept restricted as at too low temperatures the liquid metal solidifies as an undesirable skull, while at higher temperatures carbon boil will occur. Temperatures in the VRU typically range between 1350 and $1450^{\circ} \mathrm{C}$.

\section{$3 \quad$ Model for the main oxidation process in the VRU}

The model considered and progressed at MISG assumed that the chemistry in the VRU, and in particular the oxidation, could be represented as a collection of one-way chemical reactions that can each be characterised by a reaction rate. In reality the chemistry is considerably more complicated. There are further reactions taking place that are not detailed here; for example, iron and the metalloids exhibit several valencies in their oxides. Also, to some extent, the reactions included may be reversible or tend towards a dynamic balance, although the removal of oxides from the molten metal, floating to the surface as slag, will help to drive the reactions forward. The reactions within our model should be treated as representative of the overall process, the simplification providing a means to approach the MISG problem. In the model it is assumed that there is no spatial variation for the reactions, temperature or concentrations within the ladle.

The oxidation process to produce the slag is represented by two separate sets of chemical reactions. The two sets of reactions relate to the method of 
oxidising the molten metal, either using the oxygen lance or by adding the solid millscale powder.

For the chemical reactions relating to the action of the oxygen lance the oxidising agent is taken to be the compound $\mathrm{FeO}$. The oxygen lance directly blows hot gaseous $\mathrm{O}_{2}$ (at around $2000^{\circ} \mathrm{C}$ ). However, at this elevated temperature, it seems that much of the oxygen will immediately form iron oxide $\mathrm{FeO}$ at the surface of the molten liquid, as iron is the main component of the molten metal. Equation (1) describes this reaction:

$$
2 \mathrm{Fe}+\mathrm{O}_{2} \rightarrow 2 \mathrm{FeO} .
$$

The oxygen and nitrogen lances mix this iron oxide throughout the ladle where it oxidises other species. Equations (2a)-(2e) give the chemical reactions and associated reaction rates:

Reaction

$$
\begin{aligned}
2 \mathrm{~V}+3 \mathrm{FeO} & \rightarrow \mathrm{V}_{2} \mathrm{O}_{3}+3 \mathrm{Fe} \\
\mathrm{Si}+2 \mathrm{FeO} & \rightarrow \mathrm{SiO}_{2}+2 \mathrm{Fe}, \\
\mathrm{Ti}+2 \mathrm{FeO} & \rightarrow \mathrm{TiO}_{2}+2 \mathrm{Fe}, \\
\mathrm{Mn}+\mathrm{FeO} & \rightarrow \mathrm{MnO}+\mathrm{Fe}, \\
\mathrm{C}+\mathrm{FeO} & \rightarrow \mathrm{CO}+\mathrm{Fe},
\end{aligned}
$$

Reaction Rate

$$
\begin{aligned}
r_{1}^{\mathrm{V}} & =k_{1}^{\mathrm{V}}[\mathrm{V}]^{\mathrm{p}_{1}^{\mathrm{V}}}[\mathrm{FeO}]^{p_{2}^{\mathrm{V}}}, \\
r_{1}^{\mathrm{Si}} & =k_{1}^{\mathrm{Si}}[\mathrm{Si}]_{1}^{\mathrm{Si}_{1}^{\mathrm{i}}}[\mathrm{FeO}]_{2}^{\mathrm{p}_{2}^{\mathrm{Si}}}, \\
r_{1}^{\mathrm{Ti}} & =k_{1}^{\mathrm{Ti}}[\mathrm{Ti}]^{p_{1}^{\mathrm{Ti}}}[\mathrm{FeO}]^{p_{2}^{\mathrm{Ti}}}, \\
r_{1}^{\mathrm{Mn}} & =k_{1}^{\mathrm{Mn}}[\mathrm{Mn}]_{1}^{\mathrm{p}_{1}^{\mathrm{Mn}}}[\mathrm{FeO}]^{\mathrm{p}_{2}^{\mathrm{Mn}}}, \\
r_{1}^{\mathrm{C}} & =k_{1}^{\mathrm{C}}[\mathrm{C}]^{\mathrm{p}_{1}^{\mathrm{C}}}[\mathrm{FeO}]^{p_{2}^{\mathrm{C}}} .
\end{aligned}
$$

The details of the variables present in the reaction rates will be further discussed later in this report but for the present note the following. The quantity $[\mathrm{P}]$ represents the fractional concentration of the element or compound $\mathrm{P}$ present in the system. Then, $r_{1}^{\mathrm{P}}$ is the reaction rate of species $\mathrm{P}$ with $\mathrm{FeO}$, and $k_{1}^{\mathrm{P}}$ is a rate constant. The exponents of the form $p_{1}^{\mathrm{P}}$ and $p_{2}^{\mathrm{P}}$ relate to the likelihood of the necessary constituents being available.

The second oxidation process is due to the addition of millscale. This is represented by the the largest constituent which is the iron oxide compound $\mathrm{Fe}_{2} \mathrm{O}_{3}$. Equations (3a)-(3e) give the reactions and reaction rates with a similar 
notation to Equations (2a)-(2e):

$$
\begin{aligned}
& \text { Reaction } \\
& \text { Reaction Rate } \\
& 2 \mathrm{~V}+\mathrm{Fe}_{2} \mathrm{O}_{3} \rightarrow 2 \mathrm{Fe}+\mathrm{V}_{2} \mathrm{O}_{3}, \quad \mathrm{r}_{2}^{\mathrm{V}}=\mathrm{k}_{2}^{\mathrm{V}}\left[\mathrm{V}^{\mathrm{p}}{ }^{\mathrm{V}}\left[\mathrm{Fe}_{2} \mathrm{O}_{3}\right]^{\mathrm{p}_{4}^{\mathrm{V}}},\right. \\
& 3 \mathrm{Si}+2 \mathrm{Fe}_{2} \mathrm{O}_{3} \rightarrow 4 \mathrm{Fe}+3 \mathrm{SiO}_{2}, \quad \mathrm{r}_{2}^{\mathrm{Si}}=k_{2}^{\mathrm{Si}}\left[\mathrm{Si}^{p_{3}^{\mathrm{Si}}}\left[\mathrm{Fe}_{2} \mathrm{O}_{3}\right]^{\mathrm{Si}},\right. \\
& 3 \mathrm{Ti}+2 \mathrm{Fe}_{2} \mathrm{O}_{3} \rightarrow 4 \mathrm{Fe}+3 \mathrm{TiO}_{2}, \quad r_{2}^{\mathrm{Ti}}=k_{2}^{\mathrm{Ti}}\left[\mathrm{Ti}^{p^{\mathrm{Ti}}}\left[\mathrm{Fe}_{2} \mathrm{O}_{3}\right]^{p_{4}^{\mathrm{Ti}}},\right. \\
& 3 \mathrm{Mn}+\mathrm{Fe}_{2} \mathrm{O}_{3} \rightarrow 2 \mathrm{Fe}+3 \mathrm{MnO}, \quad \mathrm{r}_{2}^{\mathrm{Mn}}=k_{2}^{\mathrm{Mn}}[\mathrm{Mn}]^{p_{3}^{\mathrm{Mn}}}\left[\mathrm{Fe}_{2} \mathrm{O}_{3}\right]^{p_{4}^{\mathrm{Mn}}}, \\
& 3 \mathrm{C}+\mathrm{Fe}_{2} \mathrm{O}_{3} \rightarrow 2 \mathrm{Fe}+3 \mathrm{CO}, \quad \mathrm{r}_{2}^{\mathrm{C}}=\mathrm{k}_{2}^{\mathrm{C}}[\mathrm{C}]^{\mathrm{p}_{3}^{\mathrm{C}}}\left[\mathrm{Fe}_{2} \mathrm{O}_{3}\right]^{\mathrm{p}_{4}^{\mathrm{C}}} \text {. }
\end{aligned}
$$

Now, the evolution of the chemical species is taken to be governed by differential equations, with respect to time $t$, that correspond to the chemical reactions and reaction rates (Equations (2a)-(2e) and Equations (3a)-(3e)):

$$
\begin{aligned}
\frac{d[\mathrm{~V}]}{d t} & =-2 r_{1}^{\mathrm{V}}-2 r_{2}^{\mathrm{V}}, \\
\frac{d[\mathrm{Si}]}{d t} & =-r_{1}^{\mathrm{Si}}-3 r_{2}^{\mathrm{Si}}, \\
\frac{\mathrm{d}[\mathrm{Ti}]}{\mathrm{dt}} & =-r_{1}^{\mathrm{Ti}}-3 r_{2}^{\mathrm{Ti}}, \\
\frac{\mathrm{d}[\mathrm{Mn}]}{\mathrm{dt}} & =-r_{1}^{\mathrm{Mn}}-3 r_{2}^{\mathrm{Mn}}, \\
\frac{\mathrm{d}[\mathrm{C}]}{\mathrm{dt}} & =-r_{1}^{\mathrm{C}}-3 r_{2}^{\mathrm{C}} .
\end{aligned}
$$

So for example, in Equation (4b) the silicon present [Si] decreases at a combined rate due to oxygenation by the lance $\left(-r_{1}^{\mathrm{Si}}\right)$ and oxidation by the millscale $\left(-3 r_{2}^{\mathrm{Si}}\right)$. The coefficients of the $r_{i}^{\mathrm{Si}}$, that is -1 and -3 , are due to the stochiometric coefficients. These occur in the left-hand sides (reagents) of the chemical reactions in Equations (2b) and (3b) and reflect the number of atoms of the metalloid that reacts with the oxidising agent.

We also have differential equations governing the quantities of the oxidising 
agents and iron.

$$
\begin{aligned}
& \frac{\mathrm{d}[\mathrm{FeO}]}{\mathrm{dt}}=-3 \mathrm{r}_{1}^{\mathrm{V} \dagger}-2 \mathrm{r}_{1}^{\mathrm{Si} \dagger}-2 \mathrm{r}_{1}^{\mathrm{Ti} \dagger}-\mathrm{r}_{1}^{\mathrm{Mn} \dagger}-\mathrm{r}_{1}^{\mathrm{C} \dagger}+\mathrm{j}_{\mathrm{FeO}}, \\
& \frac{d\left[\mathrm{Fe}_{2} \mathrm{O}_{3}\right]}{d t}=-r_{2}^{\mathrm{V}}-2 r_{2}^{\mathrm{Si} \dagger}-2 r_{2}^{\mathrm{Ti} \dagger}-r_{2}^{\mathrm{Mn} \dagger}-r_{2}^{\mathrm{C} \dagger}+\mathrm{j}_{\mathrm{Fe}_{2} \mathrm{O}_{3}} \text {, } \\
& \frac{\mathrm{d}[\mathrm{Fe}]}{\mathrm{dt}}=3 \mathrm{r}_{1}^{\mathrm{V} \ddagger}+2 \mathrm{r}_{2}^{\mathrm{V} \ddagger}+2 \mathrm{r}_{1}^{\mathrm{Si \ddagger}}+4 \mathrm{r}_{2}^{\mathrm{Si} \ddagger}+2 \mathrm{r}_{1}^{\mathrm{Ti} \ddagger} \\
& +4 r_{2}^{\mathrm{Ti} \ddagger}+r_{1}^{\mathrm{Mn} \ddagger}+2 r_{2}^{\mathrm{Mn} \ddagger}+r_{1}^{\mathrm{C} \ddagger}+2 r_{2}^{\mathrm{C} \ddagger}-j_{\mathrm{FeO}}^{\ddagger} .
\end{aligned}
$$

The term $\mathfrak{j}_{\mathrm{FeO}}$ allows for the conversion of $\mathrm{Fe}$ into $\mathrm{FeO}$ on the top of the ladle due to the action of the oxygen lance. Analogously, $\mathbf{j}_{\mathrm{Fe}_{2} \mathrm{O}_{3}}$ represents the entrainment of $\mathrm{Fe}_{2} \mathrm{O}_{3}$ into the system from the addition of millscale. The addition of the symbols $\dagger$ and $\ddagger$ to factors similar to $r_{i}^{\mathrm{P} \ddagger}$ warn that, depending upon the definition of $[\mathrm{P}]$, these terms may require an extra constant factor. This will be discussed later along with the definition of $[\mathrm{P}]$ in Section 4.

We are also interested in the temperature $\mathrm{T}$ within the ladle and this is modelled using a heat balance.

$$
\begin{aligned}
c \frac{d T}{d t}= & Q_{1}^{V} r_{1}^{V}+Q_{2}^{V} r_{2}^{V}+Q_{1}^{S i} r_{1}^{S i}+Q_{2}^{S i} r_{2}^{S i}+Q_{1}^{T i} r_{1}^{T i}+Q_{2}^{T i} r_{2}^{T i}+Q_{1}^{M n} r_{1}^{M n} \\
& +Q_{2}^{\mathrm{Mn}} r_{2}^{\mathrm{Mn}}+Q_{1}^{\mathrm{C}} r_{1}^{\mathrm{C}}+Q_{2}^{\mathrm{C}} r_{2}^{\mathrm{C}}+\mathrm{Q}_{2}^{\mathrm{Fe}} r_{2}^{\mathrm{Fe}} \\
& +h_{\mathrm{FeO}}-h_{\mathrm{Fe}_{2} \mathrm{O}_{3}}-\mathrm{q}_{\mathrm{T}} .
\end{aligned}
$$

This equation has units of $\mathrm{W} / \mathrm{kg}$. The quantity $\mathrm{c}$ is the overall mean specific heat capacity of the ladle's contents (mainly molten iron). Quantities of the form $Q_{i}^{P} r_{i}^{P}$ provide the exothermal energy contributions per unit mass and time associated with the related $(\mathrm{P})$ reactions. The heat contributions due to the actions of the oxygen lance and millscale are, respectively, $h_{\mathrm{FeO}}$ and $-\mathrm{h}_{\mathrm{Fe}_{2} \mathrm{O}_{3}}$, and finally $\mathrm{q}_{\mathrm{T}}$ is due to the cooling of the ladle.

The equations in this section provide our model. There are a number of parameters that require identification and they will be considered in Section 4. 


\section{Model parameters}

Many parameters and constants are involved in the model. Some were straightforward to obtain and others proved more difficult. Aylward and Findlay [1] provided routine quantities such as molar mass. We derive values to use for a numerical illustration in Section 5. The intention is to capture typical features of the system. We begin by defining the quantities $[\mathrm{P}]$.

\subsection{Chemical variables $[\mathrm{P}]$}

Before the parameters can be identified the variables need to be defined more precisely. There was considerable debate within the 2011 MISG study group over the form the substance variables $[\mathrm{P}]$ should take. From the industrial perspective (which we shall adopt here) the most suitable quantities are the mass fractions, that is, $[\mathrm{P}]$ is the mass of $\mathrm{P}$ in a sample divided by the mass of the sample. Such measurements are made on the raw iron liquid before and after the VRU processing. However, the chemical reactions, Equations (2a)(2e) and (3a)-(3e), refer to interactions between numbers of molecules or moles of the reagent species rather than between numbers of grams of these reagents. For instance in a chemical reaction $a A+b B \rightarrow A_{a} B_{b}$, the stoichiometric coefficients $a$ and $b$ tell us that $a$ molecules (or moles) of species $A$ react with $b$ molecules (moles) of species $B$, not that a grams of $A$ react with $b$ grams of $B$. When using mass percentages, the reaction rates can be rescaled to take into account the atomic masses of the reagents. To indicate this possibility, in Equations (5a) $-(5 \mathrm{c})$, we annotated the reaction rates with $\dagger$ and $\ddagger$.

Molar fractions (moles of $\mathrm{P}$ per total moles in a sample) were considered as an easier way to handle chemical quantities in a reaction. However, it is somewhat cumbersome converting measured mass fractions into molar fractions. Additionally, trying to keep track of the total number of moles as the system evolves seems rather a steep challenge as the numbers of moles of substances on the left- and right-hand side of chemical reactions are typically 
quite different; in our example $a A+b B \rightarrow A_{a} B_{b}$ we start with a total of $(a+b)$ moles and finish with only 1 mole.

Within the mass fractions $[\mathrm{P}]$, which we decided to use within the model, the total mass of the system is also an issue to be considered. Given an initial mass of molten liquid in the ladle we are adding to the mass by a few percent through the action of the oxygen lance and incorporation of millscale. However, to balance this, the effective mass will also decrease due to the removal from the system of metalloid oxides floating to the liquid surface as slag and gas given off such as carbon monoxide (hopefully not too much). It may be possible to track the effective total mass; however, for our model we have treated it as remaining constant at its initial value.

\subsection{Rate constants}

For each reaction given by Equations (2a)-(2e) and (3a)-(3e), the associated reaction rate $r_{i}^{P}$ is required. This rate depends on the fractional mass concentration $[\mathrm{P}]$ of both the species being oxidised and the fractional mass concentration of the oxidising agent (either $\mathrm{FeO}$ from the oxygen lance or $\mathrm{Fe}_{2} \mathrm{O}_{3}$ from millscale). Furthermore, this reaction rate depends on the rate constant, $k_{i}^{P}$. For example, the reaction rates of the chemical reaction

$$
2 \mathrm{~V}+3 \mathrm{FeO} \rightarrow \mathrm{V}_{2} \mathrm{O}_{3}+3 \mathrm{Fe}, \quad \mathrm{r}_{1}^{\mathrm{V}}=\mathrm{k}_{1}^{\mathrm{V}}[\mathrm{V}]^{\mathrm{p}_{1}^{\mathrm{V}}}[\mathrm{FeO}]^{\mathrm{p}_{2}^{\mathrm{V}}}
$$

depends upon $k_{1}^{\mathrm{V}}, p_{1}^{\mathrm{V}}$ and $\mathrm{p}_{2}^{\mathrm{V}}$.

The rate constants $k_{i}^{P}$ in reality vary with temperature $T$. They decrease with temperature for all of the equations considered here (Equations (2a)-(2e) and (3a)-(3e)) apart from those that involve the oxidation of carbon which increase with temperature. A natural form to take for such rate constants is an Arrhenius relation, which has the form

$$
k=A e^{-E_{a} / R T},
$$


where $A$ is a constant prefactor that relates to the number of collisions per second, $E_{a}$ is the activation energy of the given reaction, $R$ is the gas constant, and $\mathrm{T}$ the temperature at which the reaction occurs in Kelvin. Equation (8) is the usual form for temperature dependence; however, a simple linear relationship might be an adequate model if variation is required.

The associated $p_{i}^{\mathrm{P}}$ exponents were initially thought to be the stochiometric coefficients (the number of the associated molecules that appear on the lefthand side of the chemical equations). If this is the case, then the reaction involving vanadium in Equation (7) should have $p_{1}^{V}=2$ and $p_{2}^{V}=3$. The 2 and 3 respectively correspond to the coefficients of $\mathrm{V}$ and $\mathrm{FeO}$ in the reaction. However, from further study it was clear that such exponents for reaction rates in chemical reactions do not always have this form and sometimes just have a unit exponent.

The determination of suitable $k_{i}^{P}$ and exponents $p_{i}^{P}$ for each specific reaction was the topic of much research during the 2011 MISG meeting. Unfortunately, suitable values were not found in the literature.

For the illustrative model shown in the next section (Section 5), we took the rate constants $k_{i}^{P}$ to be constant using appropriate values provided by the New Zealand Steel representatives. These are shown in Table 1. The units of these are $1 / \mathrm{s}$. The associated exponents $p_{i}^{P}$ are set to unity. If temperatures are not controlled, then the carbon reaction dependence upon temperature becomes significant and important in the potential for carbon boil.

\subsection{Mass flow rates}

The term $j_{\mathrm{FeO}}=\mathrm{J}_{\mathrm{FeO}} / \mathrm{M}_{\mathrm{T}}$, where $\mathrm{J}_{\mathrm{FeO}}$ is the mass flow rate of $\mathrm{FeO}$ entering the molten liquid and $M_{T}$ is the total mass. This is proportional to the oxygen injection rate with $\boldsymbol{j}_{\mathrm{FeO}}$ having units of $1 / \mathrm{s}$ and the units of $\mathrm{J}_{\mathrm{FeO}}$ being $\mathrm{kg} / \mathrm{s}$. Analogously, $\mathfrak{j}_{\mathrm{Fe}_{2} \mathrm{O}_{3}}=\mathrm{J}_{\mathrm{Fe}_{2} \mathrm{O}_{3}} / \mathrm{M}_{\mathrm{T}}$.

To estimate $\mathrm{J}_{\mathrm{FeO}}$ we appeal to the oxygen lance blow-rate of $1200 \mathrm{~m}^{3} / \mathrm{h}$. In 
Table 1: Reaction rates (1/s)

$\begin{array}{cc}k_{1}^{\mathrm{V}} & 0.1552 \\ k_{1}^{\mathrm{Si}} & 0.2265 \\ k_{1}^{\mathrm{Ti}} & 0.4815 \\ k_{1}^{\mathrm{Mn}} & 0.2057 \\ k_{1}^{\mathrm{C}} & 0.0546 \\ k_{2}^{\mathrm{V}} & 0.1008 \\ k_{2}^{\mathrm{Si}} & 0.1367 \\ k_{2}^{\mathrm{Ti}} & 0.3732 \\ k_{2}^{\mathrm{Mn}} & 0.1367 \\ k_{2}^{\mathrm{C}} & 0.0151\end{array}$

moles, this corresponds to about 15 moles of oxygen $\mathrm{O}_{2}$ per second (the appropriate molar volume of oxygen is approximately 22 litres). Each mole of available $\mathrm{O}_{2}$ reacts with 2 moles of iron $\mathrm{Fe}$ to produce 2 moles of iron oxide $\mathrm{FeO}$. The molar mass of $\mathrm{FeO}$ is $71.8 \mathrm{~g}$, and thus the mass flow rate $\mathrm{J}_{\mathrm{FeO}}$ is approximately $2.2 \mathrm{~kg} / \mathrm{s}$.

Now we must find the mass flow rate for millscale. Assume we are adding a discrete batch of $1100 \mathrm{~kg}$ of millscale (as is usual at the start of the process). This has to be molten and incorporated into the ladle's liquid contents which spreads the effective input of $\mathrm{Fe}_{2} \mathrm{O}_{3}$ over a five minute interval. Assuming millscale mixes into the ladle at a constant rate the effective mass flow is

$$
\mathrm{J}_{\mathrm{Fe}_{2} \mathrm{O}_{3}}=\frac{1100 \mathrm{~kg}}{300 \mathrm{~s}}=3.67 \mathrm{~kg} / \mathrm{s} .
$$

\subsection{Heat transfer and generation}

For the heat transfer equation Equation (6) we require the specific heat $\mathbf{c}$ of the molten iron. For an average batch this is approximately $450 \mathrm{~J} /(\mathrm{kg} \mathrm{K})$. 
The $h_{\mathrm{FeO}}$ and $h_{\mathrm{Fe}_{2} \mathrm{O}_{3}}$ terms represent the rate heat energy is transferred to a unit mass of the molten liquid by the mass flows and may be estimated using simple thermodynamics. For convenience, to mimic the mass flow calculations, we use $h_{\mathrm{FeO}}=\mathrm{H}_{\mathrm{FeO}} / M_{\mathrm{T}}$ and $h_{\mathrm{Fe}_{2} \mathrm{O}_{3}}=\mathrm{H}_{\mathrm{Fe}_{2} \mathrm{O}_{3}} / M_{\mathrm{T}}$, where as before $M_{\mathrm{T}}$ is the total mass of the raw liquid iron in the ladle.

Heat is generated by the interaction between iron and oxygen (from the oxygen lance) to produce iron oxide $\mathrm{FeO}$. Above the surface of the ladle temperature rises beyond $2000^{\circ} \mathrm{C}$. If we assume that the $\mathrm{FeO}$ produced is being incorporated into the ladle at $\mathrm{T}_{\mathrm{FeO}}=2000^{\circ} \mathrm{C}$, and we take the liquid temperature to be $\mathrm{T}_{\mathrm{L}}=1400^{\circ} \mathrm{C}$, then using specific heat of $\mathrm{FeO}$, $\mathrm{c}_{\mathrm{FeO}}=696 \mathrm{~J} /(\mathrm{kg} \mathrm{K})$, the rate that heat energy is added is

$$
\mathrm{H}_{\mathrm{FeO}}=\mathrm{J}_{\mathrm{FeO}} c_{\mathrm{FeO}}\left(\mathrm{T}_{\mathrm{FeO}}-\mathrm{T}_{\mathrm{L}}\right) \approx 9.2 \times 10^{5} \mathrm{~W} .
$$

This calculation is quite crude; however, we believe that the order of the contribution is correct. Similar values were obtained by different approaches using report data from New Zealand Steel.

The addition of millscale at room temperature has a cooling effect. The millscale is added in a discrete batch but it is assumed to mix into the ladle at a constant rate over a time of about five minutes. We assume likewise that the heating of the the millscale will be similarly spread over five minutes and that it is at the same temperature as the ladle contents when it reacts with the other species (Equations (3a)-(3e)). We estimate the rate energy is removed by the millscale as it heats up, from room temperature $\mathrm{T}_{\mathrm{Fe}_{2} \mathrm{O}_{3}}=25^{\circ} \mathrm{C}$ to iron liquid temperature $\mathrm{T}_{\mathrm{L}}=1400^{\circ} \mathrm{C}$, (that is, the cooling rate for the liquid iron) is

$$
\mathrm{H}_{\mathrm{Fe}_{2} \mathrm{O}_{3}}=\mathrm{J}_{\mathrm{Fe}_{2} \mathrm{O}_{3}} \mathrm{c}_{\mathrm{Fe}_{2} \mathrm{O}_{3}}\left(\mathrm{~T}_{\mathrm{L}}-\mathrm{T}_{\mathrm{Fe}_{2} \mathrm{O}_{3}}\right) \approx 3.3 \times 10^{6} \mathrm{~W},
$$

using specific heat of iron oxide $\mathrm{c}_{\mathrm{Fe}_{2} \mathrm{O}_{3}}=651 \mathrm{~J} /(\mathrm{kg} \mathrm{K})$. Again this is a fairly crude estimate, for instance we have neglected heat energy that may be involved in melting the millscale or its passing into solution; however, the value of $\mathrm{H}_{\mathrm{Fe}_{2} \mathrm{O}_{3}}$ given here is indicative of the size of this term. 
Table 2: Exothermicities $(\mathrm{J} / \mathrm{kg})$

$\begin{array}{cc}\mathrm{Q}_{1}^{\mathrm{V}} & 1.0627 \times 10^{5} \\ \mathrm{Q}_{1}^{\mathrm{Si}} & 2.6029 \times 10^{5} \\ \mathrm{Q}_{1}^{\mathrm{Ti}} & 1.7441 \times 10^{5} \\ \mathrm{Q}_{1}^{\mathrm{Mn}} & 0.6501 \times 10^{5} \\ \mathrm{Q}_{1}^{\mathrm{C}} & 1.1444 \times 10^{5} \\ \mathrm{Q}_{2}^{\mathrm{V}} & 0.5301 \times 10^{5} \\ \mathrm{Q}_{2}^{\mathrm{Si}} & 0.3324 \times 10^{5} \\ \mathrm{Q}_{2}^{\mathrm{Ti}} & 0.4120 \times 10^{5} \\ \mathrm{Q}_{2}^{\mathrm{Mn}} & 0.1212 \times 10^{5} \\ \mathrm{Q}_{2}^{\mathrm{C}} & -1.5142 \times 10^{5}\end{array}$

We assume that any millscale batch is completely absorbed by the liquid metal at five minutes after its addition and so the flux term $\mathrm{J}_{\mathrm{Fe}_{2} \mathrm{O}_{3}}$ and the heat term $\mathrm{H}_{\mathrm{Fe}_{2} \mathrm{O}_{3}}$ at that point are set to zero.

With no other processes occurring, the ladle loses $0.5 \mathrm{~K}$ per minute when it has a lid. We assume that this loss is totally due to heat conduction through the walls of the ladle and that the rate of loss is the same in the VRU when the liquid surface is either covered with slag (an insulator) or exposed to the hot flame (accounted for in $\mathrm{H}_{\mathrm{FeO}}$ ). Using the molten iron specific heat $\mathrm{c}=450 \mathrm{~J} /(\mathrm{kg} \mathrm{K})$, the cooling term is

$$
\mathrm{q}_{\mathrm{T}}=\frac{1}{2 \times 60} \times 450=3.75 \mathrm{~W} / \mathrm{kg} .
$$

Table 2 gives the other parameters required for the heat balance, the exothermicities $Q_{i}^{p}$.

Some of the estimates in this subsection are quite rough. We do not have precise measurements for everything. We ignored any effects due to variation in ladle temperature. In practice we may expect modest changes in these parameters with temperature. However, it seems reasonable to treat them as 
Table 3: Initial conditions

$\begin{array}{cl}{[\mathrm{Fe}]} & 0.9519 \\ {[\mathrm{C}]} & 0.034 \\ {[\mathrm{~V}]} & 0.0049 \\ {[\mathrm{Mn}]} & 0.0044 \\ {[\mathrm{Ti}]} & 0.0028 \\ {[\mathrm{Si}]} & 0.002\end{array}$

constant at present, both for consistency with the rate constants which are treated as constant, and as temperature variation is modest.

\subsection{Initial conditions}

To model the VRU process we must provide appropriate initial conditions for the system. There is variability between different batches of iron so we choose some typical values for use in the numerical simulation in the next section. The total mass of iron was taken as $71000 \mathrm{~kg}$ and initial temperature to be $1400^{\circ} \mathrm{C}$. The initial mass fractions are given in Table 3 .

\section{$5 \quad$ Numerical experiment}

The numerical simulation of the VRU unit was performed using the ordinary differential equations suite in the computational package Matlab. A computer program was written that solved Equations (4a)-(4e), (5a)-(5c) and (6). Initially, while using the ode45 routine built into Matlab, it was found that the system was somewhat stiff. The solver was changed to ode15s with a large improvement in the computational efficiency.

The details of most parameters and initial conditions are discussed in Section 4. 
For this simulation the oxygen lance was in continuous operation throughout. There was a single discrete addition of millscale at the start of the simulation which resulted in the terms $j_{\mathrm{Fe}_{2} \mathrm{O}_{3}}$ and $\mathrm{H}_{\mathrm{Fe}_{2} \mathrm{O}_{3}}$ being step functions with positive constant values for the first five minutes and thereafter being zero. The rates and contributions annotated with a $\dagger$ and $\ddagger$ were taken to be equal to the corresponding unmarked values.

The simulations produce the output shown in Figure 2. We emphasize that this simulation is indicative of the process rather than being an accurate representation. The levels of the metalloids decreased as they should and iron fluctuated with the inputs of oxygen and millscale. The increase in $\mathrm{FeO}$ is perhaps unexpected although iron oxide does form a significant proportion of the final slag (about a third). Also we might have expected the temperature to have risen more.

\section{Discussion}

The numerical model in the last section crudely captures the main overall features of the VRU process. However, much remains to be done to make it of practical use. One major constraint on the modelling process was the paucity of information on some of the parameters in the model and in particular the constants associated with the effective rates of chemical reactions. Late in the 2011 MISG study week, Dr Jeff Hughes from the RMIT Chemistry Department provided further advice on chemical kinetics and an alternative approach to the process. If the reactions are regarded as rapid then it may be easier to treat them as being in a dynamic balance where the equilibrium constant and hence quantities of products can be calculated from the Gibb's free energies (which are more readily available than rate constants). It was not possible to explore this approach further but the group is grateful to $\mathrm{Dr}$ Hughes for drawing it to their attention.

Within the context of the present model, we have used the estimates that 

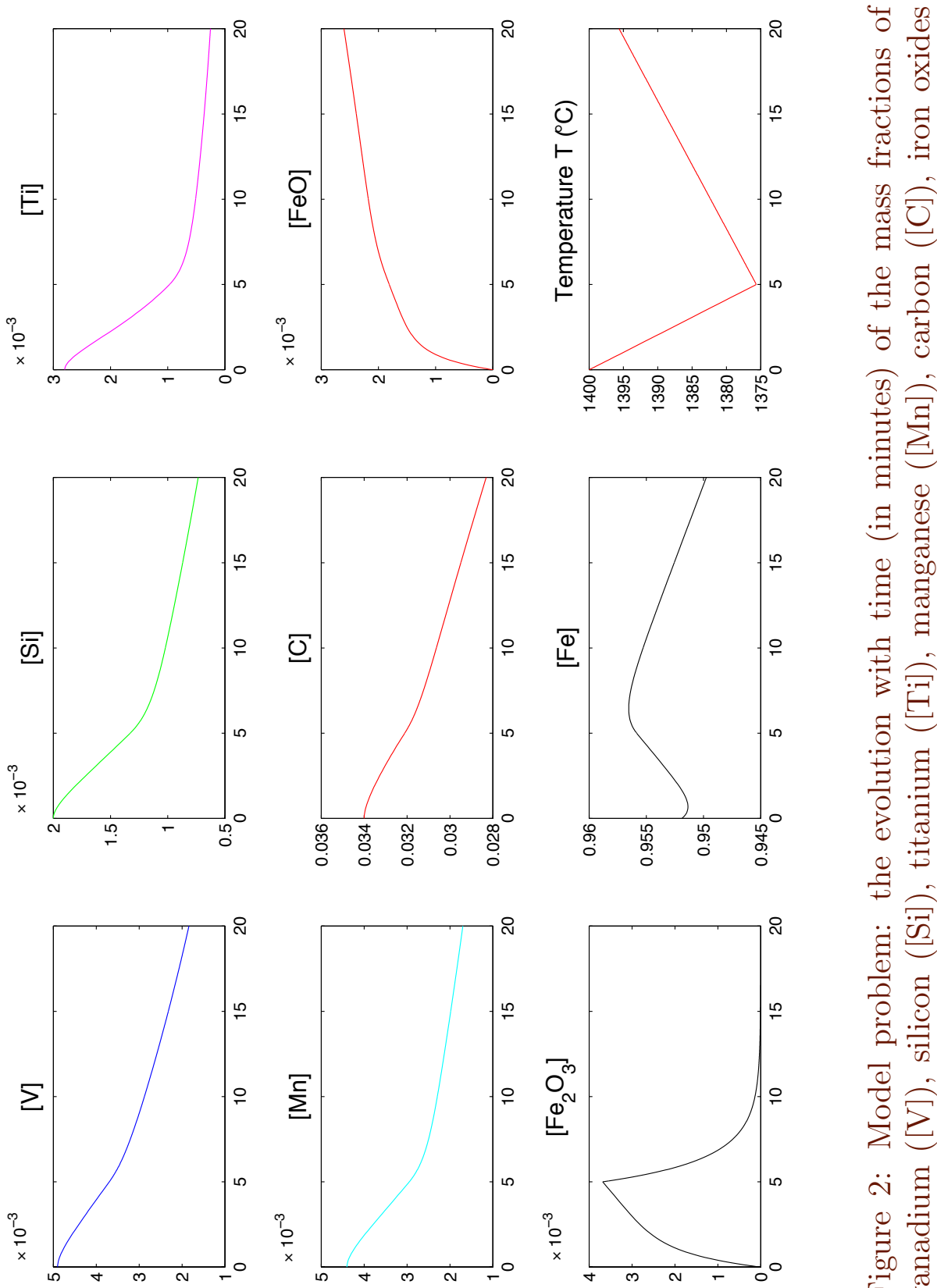

क्ञ

㕦䓃

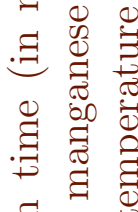

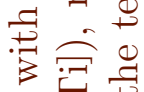

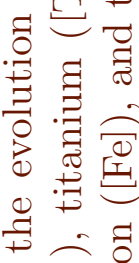

.. 氙.

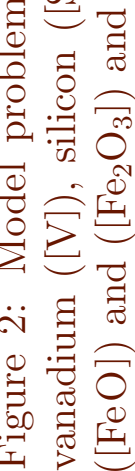


New Zealand Steel had available and more might be obtainable by laboratory work. However, it seems worth exploring an alternative approach, this is to fit model constants by a statistical analysis of the ladle composition data New Zealand Steel have on previous VRU operation. The reactions included in the model are representative of those in the real process. As a result the parameters involved may not be exactly the same.

The model, partly from necessity, misses out some of the reactions and details involved. Omissions include the presence of other iron oxides in millscale as well as $\mathrm{Fe}_{2} \mathrm{O}_{3}$. There will also be oxidation of the iron by the $\mathrm{Fe}_{2} \mathrm{O}_{3}$ :

$$
\mathrm{Fe}+\mathrm{Fe}_{2} \mathrm{O}_{3} \rightarrow 3 \mathrm{FeO} .
$$

Iron oxide $\mathrm{FeO}$ will be lost from the molten liquid both as a vapour at the reaction between oxygen from the lance and iron liquid and also as a content of the slag which is about one third iron oxide. However, as just stated the model has to be treated as a representation of the main processes within the VRU. It may be advantageous to further simplify the model, perhaps by combining the metalloids, that have a similar behaviour, into a single quantity or more closely relating the oxidation processes. Section 2 notes that the equations appeared stiff. This suggests that a submodel of fewer equations would provide a simpler and possibly adequate alternative. Further exploration of the system could be performed by numerical simulation. Also it may be possible to use asymptotic analysis to discern the dominant processes and interactions.

Some features that have not been included at present may need to be incorporated into the eventual model. For instance, we have not allowed for the addition of iron silicon alloy FeSi and this is clearly an important part of the VRU process. The model could also be adapted to allow for skulls. The effect of temperature is not included although temperature itself is modelled as it is necessary to keep temperatures within bounds. In principle many of the parameters will vary with temperature and this effect may be important.

This form of model appears amenable to the use of optimal control procedures such as the Pontryagin maximum principle [2]. Constraints include the limits 
on working temperatures to avoid skulls and carbon boil. The quantities to be determined are the duration of the oxygen lance blow, the timing and amounts of millscale addition and additions of FeSi. These are the controls available to New Zealand Steel in the VRU process. Using the maximum principle would allow one to determine their optimal value so that the vanadium concentration remaining in the vessel is as close to zero as practicable at the end of the process.

\section{Conclusions}

We have detailed work completed on the New Zealand Steel problem at the 2011 MISG study group. This considered vanadium recovery during the manufacture of steel from iron sands. A model has been developed and a numerical simulation has been used to illustrate it. Possible future developments of the model are discussed. The immediate way forward is to, first, further build upon the model simplifying the system if possible. Secondly, model parameters need to be fitted more accurately, perhaps using a statistical fit to VRU operation. Finally, an approach, using optimal control, could be developed as a tool to help plan VRU operation.

Acknowledgements We are grateful to New Zealand Steel and the Industry representatives Connal Holmes and Michael O'Connor for bringing this problem to MISG 2011 and for their valuable input. We also acknowledge and thank the other team members who worked on the problem: Syaza AbDul Latif, Jan Ding, John Gear, Tony Gibb, Ash Khan, Thiansiri Luangwilai, Dylan Pleiter, Harvi Sidhu, Kerri Spooner, Steve Taylor, Costa Theodorakopoulos, Peter Tritscher. The hospitality of our hosts at RMIT University was much appreciated and we especially thank Leanne O'Doherty and John Shepherd. 


\section{References}

[1] G. Aylward and T. Findlay. SI Chemical data. Wiley, 1994. M10

[2] S. Pontryagin, V. G. Boltyanskii, R. V. Gamkrelize and E.F. Mishchenko. The Mathematical Theory of Optimal Processes. Wiley, 1962. M19

\section{Author addresses}

1. Winston L. Sweatman, Centre for Mathematics in Industry, Institute of Information and Mathematical Sciences, Massey University, Auckland New ZEALAND.

mailto:w.sweatman@massey.ac.nz

2. Graeme C. Wake, Centre for Mathematics in Industry, Institute of Information and Mathematical Sciences, Massey University, Auckland New ZeAland.

mailto:g.c.wake@massey.ac.nz

3. Luke Fullard, Institute of Fundamental Sciences, Massey University, Palmerston North New Zealand.

4. Maria Bruna, Oxford Centre for Collaborative Applied Mathematics, Mathematical Institute, University of Oxford, Oxford UnITED KingDOM.

mailto:bruna@maths.ox.ac.uk 